\title{
Learning to teach literacy through collaborative discussions of student work
}

Marie Tejero Hughes, Michelle Parker-Katz \& Anita Balasubramanian

University of Illinois at Chicago

Despite the high numbers of students with disabilities struggling with literacy, few teachers report feeling well prepared to address it. Most students with disabilities encounter challenges in reading, and professional development can help teachers learn a range of ways to address those. In this paper, we discuss a professional development project in which prospective teachers work collaboratively with practicing teachers throughout their university preparation. The professional development provided builds on the idea of "literacy artifacts", which are samples of students' and teachers' work. Using guided discussions, teachers across the career continuum construct understandings and practices in which they learn how to infuse literacy instruction into all teaching and learning. By conjoining the literacy artifact with instructional resources teachers use, participants make visible the complexity of literacy instruction and how literacy could be embedded in teaching content for students with disabilities especially in general education classrooms.

Key words: teacher education; special education; literacy instruction

Citation: Hughes, M. T., Parker-Katz, M., \& Balasubramanian, A. (2013). Learning to teach literacy through collaborative discussions of student work. Teacher and Teaching: Theory and Practice, 19, 543-555 


\section{Introduction}

Learning to teach literacy is fundamental for all teachers, but arguably even more important for teachers of students with disabilities. Students with disabilities in particular face great challenges learning to read, obtaining information from written materials, and expressing themselves in writing (Gersten, Fuchs, Williams, \& Baker, 2001; Gajria, Jitendra, Sood, \& Sacks 2007; Mastropieri, Scruggs, Graetz, 2003; Ward-Lonergan 2010). The numbers of students impacted are staggering when we see that about $90 \%$ of students with learning disabilities have significant difficulties in reading and writing (Vaughn, LinanThompson, \& Hickman, 2003). In fact, approximately $54 \%$ of all special education students spend at least $80 \%$ of their day in general education classrooms (Data Accountability Center 2008). Furthermore, $96 \%$ of all teachers currently teach or have taught students with disabilities (SPeNSE, 2002). All teachers, therefore, need to have knowledge and skills to provide reading and writing instruction to students with disabilities.

Despite the high numbers of students with disabilities struggling with literacy in classrooms across the United States, only a third of teachers who instruct them report feeling well-prepared to address students' literacy needs (U.S. Department of Education, 2001). Yet, we know that providing professional learning opportunities focused on the necessary knowledge of literacy development and instruction could help teachers enhance students' achievement and overall success in learning disciplinary content (Moore, Bean, Birdyshaw, \& Rycik, 2000; RAND Reading Study Group, 2002). We also know that teachers with more effective literacy practices that include a repertoire of strategies and skills to support major components of reading, e.g., comprehension and fluency, secure higher student achievement gains (Brownell, Ross, Colon, \& McCallum, 2005; Haager, Gersten, Baker, \& Graves, 2003; Taylor, Pearson, Clark, \& Walpole, 2000). As well, teachers with the best student literacy gains seem to be most responsive to student needs and to differentiating instruction (Haager et al., 2003; Taylor et al., 2000). Given the challenges students with disabilities face in literacy, developing teaching practices in which explicit literacy instruction would be integrated into content instruction could help assure that students with disabilities have access to the general curriculum and can be academically successful.

In this paper we present findings on a professional development project aimed at assisting educators across the career continuum to enhance literacy instruction across content areas in order to support all students and especially those with disabilities. Though all participants in the research are special educators, they teach students with disabilities in general education classrooms in addition to other settings (e.g., resource room). Educators can learn how to integrate literacy into instruction by analyzing student work "artifacts" through ongoing and guided collaborative conversations (Parker-Katz \& Hughes, 2008); thus in this project teachers were engaged in this type pivotal kind of work. Moreover, beginning those practices early and throughout teacher preparation could help prospective teachers see the inherent worth of collaboration in teaching early in their careers and build beliefs as well as skills for effective collegial work.

Integration of literacy instruction into content-area learning could enable educators to bring about student learning that is immediately connected to individual students and to the subject matter content they are learning. In an era in which "teachers are increasingly being trained to deliver specific curricula-without regard for individual differences, 
cultural differences, and language differences" (Purcell-Gates, 2000, p.421), prospective teachers could learn during their teacher preparation programs how experienced teachers navigate those dynamics in real-life classroom situations. Experienced educators could learn new ways to provide evidence for their practices as the prospective teachers question them.

Additionally, through sustained interaction with practicing teachers, prospective teachers can make key connections between on-campus methods and foundational coursework and fieldwork to help lessen the disconnect between preparation and early career teaching so often reported (Clift \& Brady, 2005; Zeichner, 2010). In a review of university teaching practices, Risko and colleagues (2008) found that providing explicit explanations and examples, demonstrations of practices, and opportunities for guided practice of teaching strategies in practicum settings with pupils seemed most useful. Concurrently, teachers across the career continuum note concern in the quality and quantity of their preparation to support academically struggling students (Conderman \& Katzsivannis, 2002; McHatton \& McCray, 2007). Greenleaf, Jimenez, and Roller (2002) found that few teachers in their study reported knowing ways to help students develop strategies or use them to help their comprehension.

To help teachers draw on what they have studied while learning new ways to enhance their practices, we developed a professional development project focused on literacy that draws on John Dewey' notions about teacher preparation experience along with socio-cultural perspectives that relate to collaborative learning. Dewey's work informed our focus on teacher candidates. Throughout the program and prior to student teaching, we wanted to affect ways that they could come to know their students in order to develop instruction, as Dewey (1904/1965) suggested. He argued that there are two kinds of professional learning experiences pre-service teachers could have. He referred to one as the "apprenticeship", which is the traditional student teaching phase at the end of a program in which candidates learn "...the necessary tools for their profession; control of the technique of class instruction and management; skill and proficiency in the work of teaching." (p. 313). What precedes that is the "laboratory" experience when candidates focus on "making real and vital theoretical instruction; the knowledge of subject-matter and of principles of education." (p. 314). Candidates gain the skills and knowledge to make focused observations of individual students' learning and how to draw on that to frame instruction. Our professional development, therefore, was aimed at helping teacher candidates learn ways that experienced teachers watch students, draw on their strengths and challenges, and plan teaching to support student learning.

We also reasoned that professionals working collaboratively could gain skills and knowledge vital to making careful observations through collegial discussions about their hunches and considering best ways to practice. That fits with realities of increasingly collaborative ways that special and general educators interact in schools. Special educators need to gain the skills and dynamics integral to that work. Key to building such knowledge is to study the actual work professionals are charged with doing. Such work is quite situated in that it exists in a certain place, with certain people involved, at a certain time and with particular aims (e.g., student learning).

The situated nature of teaching drew us to consider socio-cultural theoretical ideas, specifically drawing on Lave and Wenger (1991) and Wenger (1998). Both argue that learning is integral to involvement in ongoing work that is carried out by individuals 
making sense of ideas and sharing beliefs together as well as on their own. When individuals are engaged, together, in the doing of something, there can develop a sense of membership, joint goals and therefore, making similar meaning of the work. Wenger (1998) further developed a robust "social learning" theory about learning in social settings. The theory posits four major components in which participants learn 1) by talking together and constructing new meanings; 2 ) by practicing together in which they share historical understandings, resources and perspectives that help them maintain a joint practice; 3 ) by talking about the ways the community can be a way to pursue and alter competence, and 4) by discussing how the actual participation in social learning through the community changes individuals' identities. The importance of professional development learning that is sustained over time seems integrally tied to Wenger's ideas and overall ways to learn in social situations just like those that special educators will encounter as they work with general educators.

Social learning perspectives, along with Dewey's arguments about dual kinds of experiences central to learning teaching, when taken together, provide a foundation for how and when teachers can learn. But given the professional development focus on literacy, we wanted also to consider what teachers needed to learn in order to integrate literacy into content area instruction. To do that, we chose a focus on implementation of comprehension strategy instruction. With a rich record over the last decade of research and ensuing evidence-based practices, we trusted that the focus would enable teachers across a range of contexts and working with a range of students to enhance reading comprehension. We defined the strategies as "specific, learned procedures that foster active, competent, self-regulated, and intentional reading" (p. 177, Trabasso \& Bouchard, 2002). Empirical research findings show common understandings about the kinds of comprehension strategies that can be integrated, as well as the kinds of strategies that should be explicitly taught (Gajria etal., 2007; National Reading Panel, 2000; RAND Reading Study Group, 2002). Moreover, researchers agree that comprehension strategy instruction could help students construct understandings of text in order to learn ways to self-monitor and incorporate learned strategies to help themselves. Given the plethora of researchbased strategies for supporting reading of content-area text and expository text in general (for instance, see Buehl, 2001; Hall, 2004; Pressley, 2002) a focus on integrating literacy into subject matter instruction to enhance students' comprehension seems appropriate. It could also become key to the collaborative work special and general educators must do.

We present research findings from experienced and prospective teachers who participated in professional development over one academic year. We posed the following research questions related to the professional development: 1) What types of literacy artifacts do experienced special education teachers select for discussions and why? 2) What purpose do experienced special educations give for selecting particular literacy artifacts and how did they perceive the discussions that emerged from these artifacts? and 3) What are the perceptions of prospective special educators' regarding the value of literacy artifacts discussions in understanding and learning about teaching.? 


\section{Participants}

\section{Methods}

Mentors. During the year, 17 experienced special education teachers participated in the role we called "mentors". Mentors came recommended by administrators, teachers, and university faculty as successful special education teachers based on observations of teaching and previous collaborative experiences. Teaching in a large urban district in the United States where the university places its student teachers, the mentors have several years of experience teaching diverse populations, differentiating curriculum, and working with students with disabilities. The schools the mentors taught were composed mostly of students from low income families (86\%), and students were from diverse backgrounds (47\% African American, 39\% Hispanic, 8\% White, non-Hispanic, 3\% Asian, 3\% other minority groups). Mentors taught students with disabilities in their schools through a variety of service delivery models (53\% inclusion, $47 \%$ self-contained special education, and 24\% resource classes) with many working in different settings throughout the day. Mentors had an average of 8.5 years $(S D=5.9)$ of teaching experience. Mentors worked with a number of different types of students with disabilities including: 71\% instructing students with high incidence disabilities (those involving largest number of students in a given class, typically with learning disabilities, emotional disabilities, or behavioral disabilities), $18 \%$ providing instruction only to students with autism, and $29 \%$ working with students with significant disabilities. Additionally, while the mentors worked with students of all ages, most (77\%) worked with students age 12 or older. Each mentor was assigned to work with two to three prospective special educators for the entire year.

Prospective special educators. A total of 43 prospective special educators participated. They were enrolled in a large research university's graduate special education program designed to enable students to obtain an initial special education teacher certification (ages 5-21). Beyond taking required coursework and completing fieldwork, each prospective special educator was connected to a mentor from their very first semester. The prospective special educators were at different points in their programs during the year the research took place. Prospective special educators entered the graduate program from a number of undergraduate disciplines including $28 \%$ education, 12\% psychology, 11\% English, 7\% science, 7\% business, 7\% fine arts, and 14\% other disciplines (e.g., theology, computers). Approximately $30 \%$ were already certified to teach in another area of education (e.g., elementary) and returned to school to obtain an additional certification in special education. Although assigned to work with one mentor, they also had access to the entire network of mentors and connected with others as needed for class assignments and fieldwork.

\section{Professional Development}

The professional development opportunity had multiple components to assist the collaboration of the experienced special education teachers and prospective special educators. One part was preparation of mentors who took on the role of leading and facilitating discussions with prospective special educators. Another part of the

professional development focused on the mentors and prospective special educators 
holding collaborative discussions during scheduled meetings, which we called field advisories, as well as discussions through email or classroom visits. The main vehicle to support those discussions was the use of "literacy artifacts." Through them, teachers demonstrated teaching and learning from their classrooms while also focusing on key literacy elements integral for students to succeed. We describe each of these now.

Mentor preparation. In order for mentors to participate in the work, we prepared them by developing their own understandings of literacy, how to integrate it in teaching, and how to draw on and use literacy artifacts from their teaching to facilitate professional conversations. Mentors attended seven professional development meetings during the year for a total of nine hours. During the first meeting of each semester mentors met for two hours with the researchers, and the agenda consisted of developing mentors' understanding of literacy in classroom teaching and learning, guiding them on selecting literacy artifacts, helping them consider the uniqueness of working with adult learners, and discussing ways to teach about teaching to prospective special educators. Mentors also practiced how to select literacy artifacts and plan discussions as well as guidelines for reflection on the discussions.

The other five one-hour mentor meetings took place immediately after regularlyscheduled meetings with the prospective special educators on campus. Mentor meeting agendas included time for mentors to discuss the results of their meetings. Additionally, we focused on a particular aspect of how to mentor using literacy artifacts and we featured a review of a specific reading focus, such as defining literacy as expressive and receptive language, learning about how to teach vocabulary, trying new strategies for teaching comprehension, and facilitating discussions about classroom artifacts. For example, at one meeting focused on identifying artifacts to demonstrate vocabulary strategies used with students, mentors discussed what their chosen artifacts helped them show about vocabulary. At another meeting, mentors identified comprehension strategies they planned to try in their classrooms, and what literacy artifacts they could select to show others what they learned. At yet another meeting, mentors devoted time to considering various ways they think and understand the word "vocabulary" and how to help their students and prospective special educators understand vocabulary as general word study.

Literacy artifacts. Mentors selected literacy artifacts from their own classroom instruction to discuss with the prospective special educators. An artifact is a sample of classroom work or materials that is significant and demonstrative of student learning, norms, routines, and/or settings (Parker-Katz \& Hughes, 2008). The idea comes in part from emerging scholarship that highlights the benefits of teachers and future educators examining classroom evidence and student work samples in order to improve instruction (Allen \& Blythe, 2004; Girod, 2002). Teachers brought in these literacy artifacts (e.g., student work samples; photos of literacy center) to share with perspective special educators and to provide a window into their planning and instruction for students in their class. After selecting the literacy artifact, mentors completed a two-part Record and Reflection Form consisting of guiding statements and questions related to the literacy artifact they were bringing (Parker-Katz \& Hughes, 2008). The primary purpose form was to assist mentors in preparing for discussion with the prospective special educators and to provide an avenue for them to think about how the discussion went afterwards. In previous 
research, it was found that mentors considered more carefully the literacy artifacts they selected and why, if they spent time planning and reflecting using these guiding questions. Thus, this form was a critical component of the professional development process of the mentors, since it served as a vehicle for them to prepare for the literacy artifact discussions and later to reflect them, thus enabling them to make changes for future discussions (Parker-Katz \& Hughes, 2008).

Prior to attending the meeting mentors recorded their responses to questions in part one of the form. The questions included the basics about the artifact such as a description, a reason for selecting it, and the literacy elements connected with the artifact. Mentors also wrote how and what they used the artifact for in their classroom and what their students learned through it. Finally, mentors wrote what they wanted prospective special educators to learn from the artifact and prepared a number of prompts or questions to help guide the discussion. The sole purpose of this part of the form was to assist mentors in their selection of appropriate artifacts and help them use their time more productively during the discussions with prospective special educators.

After meeting with the prospective special educators, mentors reflected on the discussion and completed part two of the form that consisted of questions. The goal of this activity was to assist mentors in becoming more reflective about their interactions with the perspective special educators and consider what they may want to do or change for future discussions. Mentors were asked to describe the aspects of literacy that emerged in the discussion and compare what they had planned with what actually occurred. Mentors also reflected on anything they would change or do differently as they prepared for the next time and rated their overall perceptions of the field advisory. The goal of these guiding questions was to help the mentors become more reflective of their work with the prospective special educators and assist them in planning for future discussions.

Field advisories. The mentors led the discussions and prepared their literacy artifacts for a central component of the professional development, the field advisories. Mentors and prospective special educators attended five field advisories during the year. At each mentors met with their two or three prospective special educators in a small group with another mentor and the prospective special educators he or she worked with, which resulted in groups ranging from six to eight participants. Using their Record and Reflection Form as a guide, each mentor usually took the lead for a portion of the session and began the conversation in several different ways such as raising a question about the artifact they brought, demonstrating how they used the literacy artifact, sharing information around the instruction that led to the literacy artifact, or displaying the artifact to the group and inviting comments. Sometimes mentors raised an aspect that remained unclear or presented a dilemma and used that as a way to prompt discussion. Each mentor lead the discussion around his or her literacy artifact for about half the time, and then the other mentor took about the same amount of time. Prospective special educators shared their thoughts and questions that emerged during the discussions. These discussions were very interactive in nature with all participants engaging in the conversation. During discussions, the researchers moved around and at times asked additional questions or made a comment - all aimed at sustaining the conversations. 
Additional contacts. To facilitate stronger relationships, provide individualized support, and share additional thoughts that could have occurred after the field advisories, mentors made at least two additional contacts each semester with their prospective special educators. Also, at times, the prospective special educator would complete required fieldwork hours or other assignments in mentors' classrooms.

\section{Research Instruments}

Literacy artifact. The literacy artifacts that mentors brought to the field advisories were collected or photographed (e.g., student completed concept map, teacher created story map poster). We also asked mentor's if they would be willing to share their responses with us on three items from part one of the Record and Refection form (the artifact description, the reason for selecting artifact, and the literacy elements connected with the artifact) and one from part two (reflect on the success of the discussion about the artifact) we. Although the purpose of this form was to help guide the mentors as they prepared for their discussions and for them to personally reflect on the discussions afterwards, we felt that the responses to these four guiding questions would give us a better understanding of why the literacy artifacts were selected by the mentors and their perceptions regarding the discussion itself. The responses to other prompts on the form were not shared, since this form was solely for the mentors use in their preparation and future planning. Thus, the literacy artifact itself and these four responses from the form helped us answer the first two research questions regarding what literacy artifacts were selected by the mentors and why they selected them.

Prospective teacher feedback. To answer the third research question focused on the value of literacy artifacts discussions with experience special education teachers, prospective special educators were interviewed and surveyed. Each semester prospective special educators were interviewed individually for about 15 to 20 minutes. A total of five main questions with additional probes for each question were asked. We asked about their perceptions of the usefulness of literacy artifact discussions, what they were learning regarding literacy and infusion of it into content, and their understandings of the critical components of literacy instruction for students with disabilities. For example, we asked "Your mentor has brought literacy artifacts to the field advisories, please tell me about one of them and what did you learn from the discussion about the artifact?" and additional probes for this question included "How was this artifact useful? How did it help you think about teaching students with disabilities?"

In addition, at the end of each field advisory, prospective teachers provided feedback by rating six statements using a four point Likert-type scale (1 = not very worthwhile, $4=$ very worthwhile). These statements focused on the usefulness of the discussions and artifacts in helping them understand aspects of literacy and teaching about it, if they felt they had learned from their mentors and peers, and the overall value of the field advisory. Examples of statements include "The discussion about the literacy artifacts helped me understand how other educators teach literacy," "I was able to learn ways to make individual changes to enhance individual student's opportunities to learn," and "The literacy artifacts presented gave me insight into instructing students with disabilities." Prospective teachers also provided specific written comments about the artifacts, nature of 
the discussion, and what they learned. We asked questions like, "Describe at least two things that you talked about or learned more about today." and "What specific feedback can you provide your partner regarding the selection of literacy artifacts and leading the group discussion?"

\section{Data Analysis}

Analysis procedures suggested in Miles and Huberman (1994) informed our constant comparison methods and guided the phases of examination. In the first phase of analysis, researchers reviewed data after each of the field advisories. Researchers then discussed collection of data and summarized key findings at the next staff meeting. The second flow of analysis was also implemented during data collection. As data were collected, we sought to identify ongoing findings and to organize the evidence to support or refute those findings. Data were summarized and questioned by the project staff to ensure validity and consistency in interpretation. The third flow of analysis resulted after all data collection was completed and summarized. The data were carefully reviewed and categories were created around three themes that emerged: classroom literacy artifact selection, reason for literacy artifact selection, and prospective teachers' perceptions of the literacy artifact discussions in understanding and learning about teaching. Researchers discussed these areas and individually coded the data set to further refine the findings, which were discussed and negotiated as needed until there was agreement on what findings were yielded. Percentages reported indicate the percent of time a particular response or theme was mentioned by teachers or observed across the year. In addition, data from Likert-type items were calculated for field advisories across the year.

\section{Results}

\section{Types of Literacy Artifacts}

Mentors' selection, use, and discussion of literacy artifacts seem of worth for helping prospective special educators learn to teach. Thus our first research question focused on determining what types of literacy artifacts mentors brought to share and why. We noted that the mentors brought a variety of artifacts that showed how literacy could be incorporated into all aspects of content instruction. The majority of artifacts that teachers shared (84\%) focused on enhancing reading comprehension, either solely or in conjunction with other areas of literacy. Mostly mentors chose to bring artifacts that were teachercreated instructional materials (67\%), with student work samples (22\%) being a distant second. When mentors were asked why they selected the particular artifact, the most common comments focused on selecting an artifact that showed prospective teachers how to conduct a lesson that meets a range of students' needs, as these two teachers noted, "I wanted them to see adapted ways in which to implement different aspects of literacy." and "I hope it helps them to see how to make a lesson "work" when you have a huge difference in learning abilities." The other most often stated rationale was that the artifact would help prospective teachers see the importance of connecting the lesson to their students' experiences, such as this teacher; she wanted the prospective teachers to note that "learning new words by using personal connections helps students understand." 
Mentors chose to select a different literacy artifact for each of the field advisories, rather than bringing back a previous artifact or showing an extension or follow-up from a previous one. We highlight four examples that help us show some of the qualities and range of the artifact choices. One example comes from study of a piece of literature and from a mentor who teaches in a high school language arts inclusion program. The artifact is a student's scrapbook that showed a literature character's perspective and changes over time. The mentor indicated that the artifact showed how students "...after reading a text were able to create their scrapbook by writing poems, letters and using visual images," thereby demonstrating comprehension of the text. Another mentor, who taught high school students with autism, brought a "social script of a photograph" that was designed to help students "relate reading to the thoughts they have about pictures," and see how reading, speaking, listening, writing, and comprehension are interconnected. Furthermore, "It (the artifact) helped them (students) see words/sentences could be formed by what they were thinking while looking at a picture they enjoy." The mentor went on to say that it got the prospective teachers thinking about "how to create literacy (opportunities) for nonreaders."

In yet another example, a mentor who taught in an elementary resource class brought in a "board game designed by students" and she chose it because it emphasizing how writing, speaking and listening are intertwined. The mentor indicated that working on the board game "forces students to really think about following directions, since they must develop and test their own rules for games they develop. It also requires the students to edit their directions so that they are simple and clear." A final sample artifact comes from an elementary classroom for children with autism. The partner brought in a Picture Exchange Communication (PECs) book he designed for one of his non-verbal students in which he had pictures taped to Velcro strips. The mentor chose this artifact to focus on the communication aspect of literacy - "How do nonverbal students communicate? How can they expressively use new vocabulary? How to teach new vocabulary?" The mentor noted that he wanted to emphasize that "all students are capable of learning new vocabulary" if appropriate adaptations are considered.

\section{Purpose and Response to the Literacy Artifact}

Our second focus was to understand mentors purpose for of selecting particular literacy artifact and how they felt the discussion related to the artifacts went. Mentors identified several aspects of teaching that they tried to highlight for prospective teachers through discussions surrounding the literacy artifact. These included making adaptations and modifications during instruction (67\%), engaging and motivating students with disabilities (64\%), creating instructional design, planning, and implementation of lessons (39\%) and integrating content and literacy goals (35\%). Mentors explained their aims through statements like, "I would like them to see how you can adapt a lesson even if you have a broad range of levels in your class." Or, "This [artifact] allows students to access the general curriculum and other learning materials and activities", or "[I wanted them to think about] how do you go about teaching new vocabulary to someone who is non-verbal?"

Most mentors considered their discussions during meetings to be successful if they could generate interest in their group about their literacy artifacts while helping 
prospective teachers make connections with teaching. "[University] students had good questions that came from the artifact and discussion," said one mentor. "I think I saw a light bulb go off with some people regarding the different ways we might meet reading goals," said another. In total, $60 \%$ of the mentors indicated that during field advisories they demonstrated and described artifact use, and $49 \%$ of mentors also reported asking questions of prospective teachers to engage them in discussions. Mentors made statements like: "I demonstrated how to make the artifact, how to use it, get students to identify words in categories." and "[I] asked for feedback and what they might use this bookmark for." While $67 \%$ of the responses suggest that mentors were satisfied with the field advisories, some responses also showed reflection about what they planned to change in the future (49\% of responses). Here are two examples: "I want to present something that is in process. Have them work at what outcomes can be made or create lessons to address such." And, "Next time I would like to bring a hands-on demonstration that the students could do as if I was doing it with the students in my classroom."

\section{Prospective Teachers' Perceptions}

Our final question had us looking closely at how the prospective teachers felt about these literacy artifact discussions with their mentors. Overwhelmingly, prospective teachers provided positive feedback about the discussions and highly complimented the types of literacy artifacts mentors brought in. They made comments such as, "I love the artifacts you (the mentor) bring for the profound population, and the way vocabulary frames were modified for high school students" or "Artifact was terrific and her conversational skills equally informative, substantive, simple, and imaginative." Furthermore, prospective teachers reported how discussions helped them align what they learned in coursework with what could happen in classrooms. They made statements such as, "I like the connection between a real classroom environment and real experience that she can share with us." or "I like it because it helps me get a bigger picture of what teaching is going to be like."

Analysis of the prospective teachers' interviews shows that they could recall and discuss artifacts from their meetings weeks later. They found the literacy artifacts very relevant and useful. They also reported finding discussions and the actual artifacts helpful as they thought about making modifications and adaptations in their own teaching. Prospective teachers made statements like "Everything they show helps me think about how I could modify things for an inclusion setting." Or "I thought that was really creative and took the idea back to my school to see if we could do something like that." Or "He brought in pictures of the learning centers in his classroom." Prospective teachers highlighted the discussion of educational issues with peers and mentors (58\%), learning from the experiences of mentors (58\%), and students' self-professional growth (45\%) as three major overall gains from the field advisories. "Course work does not deal with these things that are peripheral. These discussions provide a space for that." And "There's a sense of developing a professional identity as a special education educator that's done by developing a relationship with someone who's already in the field." Or "I like the connection between a real classroom environment and real experience that she can share with us." 
Student feedback collected at the end of the field advisories also show clear evidence of worth with $98 \%$ of the responses across the year indicating that discussion of the literacy artifacts gave an insight into instructing students with disabilities in a range of settings. Furthermore, $67 \%$ of prospective teachers strongly agreed that field advisories provided them with information that enhances their knowledge of teaching literacy to students with disabilities, while $32 \%$ agreed this was the case.

\section{Discussion}

As a result of this investigation we learned that experienced special educators selected a wide array of literacy artifacts to share with prospective teachers, although the vast majority mentors chose to bring artifacts that focused on developing their students' reading comprehension, but did bring different artifacts to each field advisory. Experienced special educators also indicated that the primary reason they selected particular artifacts was to highlight to prospective teachers how individual student needs can be met by making adaptations to lessons and activities. In general mentors felt that their discussions around these literacy artifacts went well and that prospective teachers were engaged and interested. Prospective teachers second this feeling by indicated they felt quite positive about these discussions with the experienced special educator and stated that they learned a great deal about instructing students with disabilities from these literacy artifacts.

This findings are promising given that we designed this professional development for early and experienced educators focused on identifying how mentors could help create opportunities outside of classroom observations for prospective special educators to learn about designing and implementing literacy instruction for students with disabilities. We also wanted at the same time to develop and assess the potential benefits of developing a collaborative community of educators. With the growing number of students with disabilities educated within general education settings in the United States (Data Accountability, 2008;), and research findings indicating that a majority of those students struggle with reading, the kind of professional development we present here could be pivotal in order to enhance special educators' knowledge and skills to integrate literacy instruction into content area instruction. Those special educators could in turn help general educators as they collaborate to provide services to students with disabilities. Moreover, professional development that unites early and experienced educators in collaborative study could have great worth in inducting new special educators into the collaborative teaching they will be expected to practice. Linking that practice to teaching literacy strategies during content instruction could help all educators support students with disabilities in a range of settings.

Overall, we learned that use of classroom literacy artifacts as a source for discussion of teaching and learning between early and experienced special educators shows promise as a professional development vehicle. Through discussion of literacy artifacts, special educators can learn practical ways to supports students' learning of literacy through content-area instruction, serve a range of learners' needs, and highlight multiple ways to differentiate instruction in order to serve those needs. Furthermore, collaborative discussions focused on students' work could enhance all participants' learning. We identify three major conclusions, with implications, for collaborative professional development and research. We also nest our findings in broader discussions about how we can create new 
spaces in which practicing teachers' knowledge can contribute to teacher education and professional development (Cochran-Smith \& Lytle, 1999; Zeichner, 2010).

Literacy and professional development. Firstly, we see the positives of a promising professional development for educators that at its core includes a focus on students with disabilities learning the literacy necessary to access the general curriculum. Teachers discussed approaches to support needs of students with disabilities who struggle with literacy. Mentors learned ways to focus prospective special educators on the literacy skills and understandings that could enhance their future students' learning. This was initially difficult for many mentors, since although accomplished at working with students, many never had to translate their planning and decision making process to other adults. Also, selecting literacy artifacts proved to be more complex that initially perceived by many of the mentors. Over the course of the year, mentors reported spending more time carefully considering the artifact and truly understanding what they wanted others to gain from it. As a result, it appear that mentors also studied aspects of their practices very closely in order to choose the artifact, plan discussion and consider what they learned in addition to the prospective teachers. At the same time, the prospective special educator could pose questions and gather information based on real-life teaching dilemmas, too, in the safe environment of small-group conversations. They could begin to shape their teacher identities as special educators, through the slices of classroom life they studied through the artifact discussions. They could also imagine what they could encounter, and how they might respond and gain feedback about that thinking.

Key to the professional development is the use of literacy artifacts that allow teachers across the career continuum to discuss practice focused on students' learning. As Hawkins (1974) argued, the role of the teacher is to connect students with learning content in a seamless and ongoing flow of activity and thought. Seeing those connections is pivotal to special educator preparation given that often the focus of special education is on the characteristics of students and their abilities with less concurrent focus on how students with disabilities learn academic content. In subsequent professional development research, we now have teachers gather literacy artifacts that focus on students' work and the related resources and lesson plans they used (Hughes \& Parker-Katz, 2013).

Mentor professional development. Because experienced teachers traditionally participate only at the end of the university preparation program (e.g., student teaching), mentor preparation content is usually focused on topics specific to prospective teachers taking on the tasks of teaching full-time (e.g., preparing lessons, handling management). However in this professional development, mentor interactions are integrated into university preparation at the beginning and sustained throughout university students' studies. Since mentors' preparation happens concurrently with prospective teachers' coursework and field experiences, mentors learn to connect their artifacts and discussions with challenges prospective teachers suggest from those experiences.

A focus on research-based literacy instruction and how that can happen aligns with research findings from two decades of studies (e.g., Blair, Rupley, \& Nichols, 2007). But, we added the focus on examining student' work (Allen \& Blythe, 2004; Carini, 2004) and how collaborative teacher analyses and discussions can provide "knowledge for practice" (Cochran-Smith \& Lytle, 1999) in which teacher inquiry forms the basis for teachers 
developing understandings to inform practice. In our project, we aimed to teach mentors to examine their own practice while learning how to help prospective educators do the same. We hoped mentors could induct prospective teachers into a habit of doing close examination of students and their learning while also providing them with a repertoire of instructional strategies.

Literacy professional development across a career. A third major conclusion is that professional development for early and experience special educators could highlight the complexity of literacy instruction and how it could be embedded in teaching academic content. The discussions help make transparent the planning and organization necessary in good instruction, how teachers take into account individual students and the class as a whole in making instructional choices, and how teaching literacy to enhance learning academic content could happen. Prospective special educators appreciated hearing how mentors critiqued their own practices, assessed their students' learning and dealt with dilemmas about it, and mapped out next steps. Such collaborative talk helps new special educators learn to determine the literacy needs of students with disabilities, as well as learn ways to incorporate literacy into content learning. Planning instruction and assessing learning with a focus on literacy is often completely hidden from view as prospective teachers complete course work. In this project, mentors learned ways to think aloud to each other and how what they say, and how, might be interpreted differently by a prospective versus experienced educator.

\section{Collaboration and Teacher Knowledge}

When early and experienced special educators collaborate around literacy instruction, as they did in this professional development, we saw a change in the ways educators construct understandings of teaching. Those understandings contribute to the quality of instruction and to what students can learn (Brownell, Ross, Colon \& McCallum, 2005; Brownell, Adams, Sindelar, Waldron \& Vanhover, 2006). Cochran-Smith and Lytle (1999) argue that how we perceive teacher knowledge - the content, processes for learning and constructing it, and ways it is enacted - rests upon many assumptions. In "knowledgefor-practice", teachers draw on knowledge generated from university-based research while in "knowledge-in-practice", teachers draw on both their own constructs and those ideas learned from a broad array of master teachers. A third viewpoint is that teachers draw on knowledge they generate through purposeful explorations of their instruction along with critique of theory and others' ideas. "Teachers learn when they generate local knowledge of practice", they write, "by working within the contexts of inquiry communities to theorize and construct their work and to connect it to larger social, cultural and political issues." (p. 250). When looking at literacy artifacts and having purposeful discussions, teachers take into account the dynamics of culture and socio-political elements and generate new questions to inform their teaching.

Moreover, no longer are teachers wholly relying on traditional university-based research and interpretations that are at times removed from the authentic dilemmas of classroom life. Whereas traditionally knowledge emerging from the university was viewed as the authoritative source, we now see how knowledge from a range of sources in schools and external communities can create what Zeichner (2010) sees as "hybrid spaces" in pre- 
service teacher education. In such situations, we would "bring practitioner and academic knowledge together in less hierarchical ways to create new learning opportunities for prospective teachers." (p.92) Bringing together teachers from across the career continuum to collaborate with university teacher educators, we would add, could transform teacher preparation along with the knowledge of teaching and the structures through which we all could learn teaching.

\section{References}

Allen, D., \& Blythe, T. (2004). The facilitator's book of questions: Tools for looking together at student and teacher work. New York: Teachers College Press.

Blair, T.R., Rupley, W.H., \& Nichols, M.D. (2007) The effective teacher of reading: Considering the "what" and "how" of instruction. The Reading Teacher, 60, 432-438.

Brownell, M.T., Ross, D.D., Colon, E.P., \& McCallum, C.L. (2005). Critical features of special education teacher preparation: A comparison with general teacher education. Journal of Special Education, 38, 242 - 252.

Brownell, M.T. Adams, A., Sindelar, P., Waldron, N., Vanhover, S. (2006). Learning from collaboration: The role of teacher qualities. Exceptional Children, 72, 169-185.

Buehl, D. (2001). Classroom strategies for interactive learning. Newark, DE: International Reading Association.

Carini, P.F. (2000). A letter to parents and teachers on some ways of looking at and reflecting on children. In M. Himley \& P.F. Carini, (Eds.), From another angle: Children's strengths and school standards (pp. 56 -65). New York: Teachers College Press.

Cochran-Smith, M. \& Lytle, S. (1999). Relationships of knowledge and practice: Teacher learning in communities Review of Research in Education, 24, 249- 305.

Conderman, G. J., \& Katsiyannis, A. (2002). Instructional issues and practices in secondary special education. Teacher Education and Special Education, 23, 167-179.

Clift, R.T., \& Brady, P. (2005). Research on methods courses and field experiences. In M. Cochran-Smith \& K.M. Zeichner (Eds.), Studying teacher education: The report of the AERA panel on research and teacher education (pp. 309-424). Mahwah, NJ: Erlbaum.

Data Accountability Center. (2008). Profiles of Parts B and C Programs in States and Outlying Areas, 2001-02 through 2006-07. Retrieved from https://www.ideadata.org/TrendDataReports.asp

Dewey, J. (1964/1904). The relation of theory to practice. In R.D. Archambault (Ed.) John Dewey on education. Chicago: University of Chicago Press. p. 313 - 339.

Gajria, M., Jitendra , A.K., Sood, S., Sacks, G. 2007. Improving comprehension of expository text in students with LD: A research synthesis. Journal of Learning Disabilities 40: 210-225.

Gersten, R., Fuchs, L.S, Williams, J.P., Baker, S. (2001). Teaching reading comprehension strategies to students with learning disabilities: A review of research. Review of Educational Research, 71, 279-320.

Girod, G. R. (2002). Connecting teaching and learning: A handbook for teacher educators on teacher work sample methodology. New York: AACTE. 
Greenleaf, C. L., Jimènez, R. T., \& Roller, C.M. (2002). Reclaiming secondary reading interventions: From limited to rich conceptions, from narrow to broad conversations. Reading Research Quarterly, 37, 484-496.

Haager, D., Gersten, R., Baker, S., \& Graves, A. (2003). The English language learner observation instrument for beginning readers. In S. Vaughn \& K. L. Briggs (Eds.), Reading in the classroom: Systems for the observation of teaching and learning. Baltimore, MD: Brookes.

Hall, L. A. (2004). Comprehending expository text: Promising strategies for struggling readers and students with reading disabilities? Reading Research and Instruction, 44(2), 75-95.

Hawkins, D. (1974). I, Thou and It. In D. Hawkins. The Informed Vision: Essays on Learning and Human Nature. New York: Agathon Press. Pp. 48 - 63.

Hughes, M. T. \& Parker-Katz, M. (2013, April). Professional collaboration designed to meet the needs of students with disabilities in content area classes. Presentation at the annual meeting of the American Educational Researcher Association. San Francisco, CA.

Lave, J. \& Wenger, E. (1991). Situated learning: Legitimate peripheral participation. Cambridge: Cambridge University Press.

Mastropieri, M., Scruggs,T., Graetz, J. (2003). Reading comprehension instruction for secondary students: Challenges for struggling students and teachers. Learning disability quarterly; 26(2), 103-117.

McHatton, P.A., \& McCray, E.D. (2007). Inclination toward inclusion: Perceptions of elementary and secondary education teacher candidates. Action in Teacher Education. 29 (2): 25-32.

Miles, M.B., \& Huberman, A.M. (1994) Qualitative data analysis: An expanded sourcebook, $2^{\text {nd }}$ ed. Thousand Oaks, CA: Sage.

Moore, D. W., Bean, T. W., Birdyshaw, D., \& Rycik, J. A. (2000). Adolescent literacy: A position statement for the Adolescent Literacy Commission of the International Reading Association. Newark: DE: International Reading Association.

National Reading Panel. (2000). Teaching children to read: An evidence-based assessment of the scientific research literature on reading and its implications for reading instruction: Reports of the subgroups. (NIH Publication No. 00-4769). Washington, DC: U.S. Government Printing Office.

Parker-Katz, M. \& Hughes, M. T. (2008). Preparing special education mentors: Classroom artifacts as a vehicle for learning teaching. Teacher Education and Special Education, $31,268-282$.

Pressley, M. (2002). Metacognition and self-regulated comprehension. In A.E. Farstrup \& S. Samuels (Eds). What research has to say about reading instruction (p. 291- 309). Newark, DE: International Reading Association.

Purcell-Gates, V. (2000). What will be the social implications and interactions of schooling in the next millennium? Reading Research Quarterly, 35, 421-422.

RAND Reading Study Group. (2002). Reading for understanding: Toward an R\&D program in reading comprehension. Santa Monica, CA: Author.

Risko, V.J., Roller, C.M., Cummins, C., Bean, R.M., Block, C.C., Anders, P.L. \& Flood, J. (2008). A critical analysis of research on reading teacher education. Reading Research Quarterly, 43, 252-288. 
SPeNSE. (2002). General education teachers' role in special education: Study of personnel needs in special education. Retrieved from: http://ferdig.coe.ufl.edu/spense/

Taylor, B.M., Pearson, P.D., Clark, K., \& Walpole, S. (2000). Effective schools and accomplished teachers: Lessons about primary-age reading instruction in lowincome schools. Elementary School Journal, 101, 121-165.

Trabasso, T., \& Bouchard, E. (2002). Teaching readers how to comprehend text strategically. In C.C. Block \& M. Pressley (Eds.), Comprehension instruction: Research-based best practices (pp. 176-200). New York. Guilford.

U.S. Department of Education. (2006). Office of Special Education Programs, Individuals with Disabilities Education Act (IDEA) database. Retrieved from https://www.ideadata.org/tables29th/ar_2-2.xls.

U.S. Department of Education: National Center for Education Statistics (2001). Teacher preparation and professional development: 2000. NCES 2001-088, Washington, DC.

Vaughn, S., Linan-Thompson, S., \& Hickman, P. (2003). Response to instruction as a means of identifying students with reading/learning disabilities. Exceptional Children, 69, 391-409.

Ward-Lonergan, J. M. 2010. Expository discourse intervention: Helping school-age children and adolescents with language disorders master the language of the curriculum. In M. Nippold, and C. Scott (Eds.), Expository discourse in children, adolescents, and adults. Development and disorders (pp. 241-273). New York: Psychology Press.

Wenger, E. (1998). Communities of practice: Learning, meaning and identity. Cambridge: Cambridge University Press.

Zeichner, K. (2010). Rethinking the connections between campus courses and field experiences in college and university-based teacher education. Journal of Teacher Education, 61, 89 -99. 